\title{
A Proposal of Consumer Driven Framework for Enabling Sustainable Production and Consumption
}

\author{
Jing Shao \\ Dept. of Management, Economics and Industrial Engineering, \\ Politecnico di Milano, Milan, Italy \\ Jing.shao@polimi.it \\ Marco Taisch \\ Dept. of Management, Economics and Industrial Engineering, \\ Politecnico di Milano, Milan, Italy \\ Miguel Ortega Mier \\ Dept. of Industrial Engineering, Business Administration and Statistics, \\ Universidad Politécnica de Madrid, Madrid, Spain
}

\begin{abstract}
Sustainability becomes the key towards success of manufacturing industries now. Besides increasing efficiency of sustainable industrial processes, sustainable consumption becomes an important complementary strategy for making economies more sustainable gradually. Hence, the research in sustainable production and consumption ( $\mathrm{SPaC}$ ) keeps emerging and the approach of information transition became noticed as the key to promote SPaC. Therefore, there is a notable need for generating proper approach in order to achieve the goal of providing sustainable information of a product for consumers has been discussed.

This paper is looking forward to support the implementation of SPaC by developing a framework aimed at providing sustainable information of a product for consumers. Aspects and attributes have been elicited, and a novel metrics of attributes integrate with life cycle has been developed. Furthermore, a conceptualized framework aimed at evaluating social and environmental performances of a product in its production phase has been developed.
\end{abstract}

Keywords: Facilitator, $\mathrm{SPaC}$, indicator, framework, consumer driven

\section{Introduction}

Consumers are key to driving sustainable production and play a central role in sustainable development (OECD 2008). Presently, consumers, even though green consumers could not get sufficient information that enable them making greener buying decisions. There is a notable need for generating proper approach or strengthening available approaches in order to get the goal of providing sustainable information of a 
product for consumers. In order to enable information transition from sustainable production to sustainable consumption, facilitator was defined as "Laws, policies and administrative procedures" in AFI framework (Akenji 2014). It is the key element in the whole system and could properly reflect consumers and other stakeholders' attitudes, and it is assured to be function well with the help of infrastructures. From literatures, many kinds of approaches have potential to play the role of facilitator and provide sustainability information for consumers. However, from a systematic review on available approaches, it is showed that in both industrial engineering and marketing science, available approaches or instruments could hardly be directly applied for consumers (Taisch and Shao 2013; Shao et al. 2014).

One of the most possible ways of generating facilitator to achieve the goal is to measure sustainability of a product. The instrument could be generated by applying industrial engineering approach and face to stakeholders through appropriate presenting method. Indeed, in last several decades, indices are commonly used approaches for attracting attention and often simplify the problem in order to make the impact of energy consumption and environmental impacts visible in industrial engineering (Bell and Morse 2008). And they are beneficial for policy making and public communication in sending information of countries' performances about environment, energy, society and economy (Amacher et al. 2004). Although it is challenging for researchers to cover all topics at the same time, it is still possible to launch by squeezing objective scope to consumers who direct relevant to buying decisions.

This paper will propose a consumer driven framework for enabling sustainable production and consumption by providing sustainability performance information of a product for consumers. This framework is designed to select possible attributes which used to evaluate social and environment performance, from which companies can choose to assess sustainability for their products associated with manufacturing. We used methodology of seven steps of "Sustainability evaluation process" (Joung et al. 2012) to assess sustainability and employed "Stepwise approach to development of environmental indicators" (Olsthoorn et al. 2001) to select proper indicators. After reviewing on attributes in available sustainability assessments, and considering the objective of this research, a conceptualized framework of facilitator focusing on social and environmental impact in the production phase has been generated.

\section{$2 \quad$ Methodology}

\subsection{Steps of Sustainability Assessment}

Indices for assessing sustainability adopt different constructing steps (Singh et al. 2007; Lehni 1999; Joung et al. 2012). In this research, the methodology adopted is the seven-step "Sustainability evaluation process" (Joung et al. 2012) (Shown in Table 1). The choice was made based on its property of general applicability of generating single indicator in sustainability assessment.

Table 1. 7 Steps of Sustainability evaluation process (Source: Joung et al. 2012)

\begin{tabular}{|l|l|}
\hline Step 1 . Set sustainability objective & Step 2 . Select indicators \\
\hline Step3. Specify measurement procedures & Step4. Analyze data \\
\hline
\end{tabular}




\begin{tabular}{|l|l|}
\hline Step 5.Report & Step 6. Make managerial decision \\
\hline Step 7. Evaluate impact & \\
\hline
\end{tabular}

From previous study (Taisch and Shao 2013) (Shao, J., 2014b), the sustainability objective has been fully discussed and well defined as: provide sustainability performance information of a product for consumers in order to make collaborative buying behavior become an incentive for greener manufacturing possible. In Step 2, even though set of indicators are chosen and decided by experts, it is a subjective process since selection of the right set of indicators depends on many factors, such as the type of product, type of processes, final reporting format, budget, approvals required, market, and time availability. Therefore, in this paper, we focused on step 2 "selecting indicators" and the methodology of choosing appropriate indicators will be discussed in the following section.

\subsection{Top-Down Approach for Selecting Indicators}

A stepwise protocol to develop appropriate sustainable indicators was proposed by Olsthoorn, X., as shown in figure 1 (Olsthoorn et al. 2001). It is a general protocol for generating environmental indicator that starts from available data collection and then proceeding with normalization, aggregation, together with standardization. An indicator will be presented for its data users at the end.

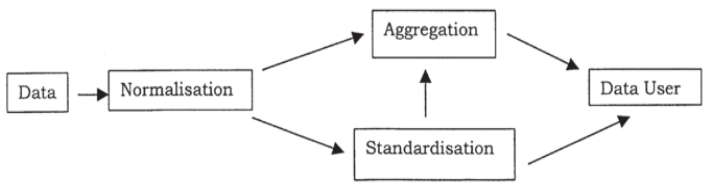

Fig. 1. Stepwise approach to development of environmental indicators (Source: Olsthoorn et al. 2001)

Compared to above commonly applied stepwise protocol for developing general sustainable indicator, this study focused on providing meaningful, accurate, relevant and cost-effective information for consumers. Therefore, a high emphasis has been put on research on the information needed of consumers.

The selection of key attributes is a crucial task in this study. The very first time the four basic rights which includes safety, information, choice and legal representation of consumer were declared by US President John Kennedy in 1962. Later, the rights to the satisfaction of basic needs, redress, consumer education and a healthy environment were added and adopted by The United Nations in 1985 (Ha et al. 2009). Harrison et al. (2005) have proposed some external factors that influence the growth of ethical consumer consumption- a variant of sustainable consumption (Harrison et al. 2005). And "social and environmental effects of technological advance" was the first dimension of all the perspectives. Therefore, in order to promote sustainable consumption, only sustainability assessment information should be included in this 
framework, and furthermore, only the information on social and environmental impact of a product should be included.

\section{$3 \quad$ Life Cycle Integrated Metrics}

In the field of sustainability assessment, numerous indicators were developed by researchers and practitioners. Past research on reviews of sustainability indicators from the perspective of industrial engineering are common to see (Singh et al. 2009; Arena et al. 2009; Dahl 2012). Various weighting methods of composite indexes have been summarized in (Freudenberg 2003). A full list of sub-categories of sustainable performance assessment of a country and involved indicators, plus their related information such as definitions, calculation methods and references were reviewed in the literature (CSD 2001). Literatures on achievements and challenges regarding measuring sustainable development were proposed by Organization for Economic Cooperation and Development (OECD 2009) .

\subsection{Dimension and Aspects Comparison of Indices}

From systematic review of available indicators, six publicly available indicators which associate with social and environmental performance assessment have been selected to have a detail study and analysis on (Shao et al. 2014b). Table 2 shows the list of dimensions of the index. Two main streams of indicator generation could be found in the list of dimensions of indices. One stream is generated in line with the three pillars of sustainability (Brundtland 1987). Impact of social, environmental, and economic performances have been assessed by sub-indicators. Some of them added extra dimensions, such as "well-being" (e.g., CS), or "technical aspects" (e.g., CSPI), or "cost house" (e.g., LInX), to have a complementary list of assessment measures (Reference see Appendix A).

Table 2. Comparison of dimensions of index

\begin{tabular}{|c|c|c|c|c|c|c|}
\hline & CS & CSPI & F-PSI & EPI & G score & E99 \\
\hline Environmental Health & & $\mathrm{x}$ & $\mathrm{x}$ & & & \\
\hline Societal & $\mathrm{x}$ & $\mathrm{x}$ & $\mathrm{x}$ & & & \\
\hline Economics & $x$ & $\mathrm{x}$ & $\mathrm{x}$ & & & \\
\hline Organizational Governance & & $\mathrm{x}$ & & & & \\
\hline \multicolumn{7}{|l|}{ Well-being } \\
\hline \multicolumn{7}{|l|}{ Technique } \\
\hline Production Phase & & & $\mathrm{x}$ & & $\mathrm{x}$ & $\mathrm{x}$ \\
\hline Use Phase & & & $\mathrm{x}$ & & $\mathrm{x}$ & $\mathrm{x}$ \\
\hline End of life & & & $x$ & & $\mathrm{x}$ & $\mathrm{x}$ \\
\hline
\end{tabular}

Another stream of indicators considered life cycle assessment as an important approach when measuring the sustainability of product, so production, using and disposal phases of a product have been regarded as dimensions in this indicator, e.g., E99. In addition, G Score focuses on the production phase of a product, combine with environmental impact. F-PSI has considered both two streams of generation approach and 
combine sustainability dimensions with life cycle dimensions. This study adapts with definitions of themes and sub-themes in the literature (CSD 2001).

\subsection{Life Cycle Integrated Metrics}

In order to carry out the novel metrics integrated life cycle process, a hierarchical diagram is defined using a top-down approach. It includes Dimensions, Aspects and Attributes.

Table 2. Metrics of attributes in Consumer Driven Framework with life cycle

\begin{tabular}{|c|c|c|c|}
\hline & Social Impact & Environmental Impact & \\
\hline Production & $\begin{array}{l}\text { Human : } \\
\text { Employee Training } \\
\text { Employee participation } \\
\text { (human right) } \\
\text { Child labor } \\
\text { Working safety } \\
\text { Company image: } \\
\text { Law suit } \\
\text { Local community } \\
\end{array}$ & $\begin{array}{l}\text { Material: } \\
\text { Reuse/recycling of resource (energy, } \\
\text { material, product) } \\
\text { Raw Material Extraction } \\
\text { Specific Raw material consumption } \\
\text { Energy Using: } \\
\text { Energy Efficiency } \\
\text { Renewable Energy } \\
\text { Specific energy consumption }\end{array}$ & \multirow{5}{*}{$\begin{array}{l}\text { Nature: } \\
\text { Life cycle Air } \\
\text { Quality } \\
\text { Water Consumption } \\
\text { Regional Ozone } \\
\text { Urban Particulates } \\
\text { Biodiversity and } \\
\text { Habitat } \\
\text { Average noise level } \\
\text { in the periphery of } \\
\text { plant dB(A) }\end{array}$} \\
\hline Transportation & & & \\
\hline Using & $\begin{array}{l}\text { Customer health \& } \\
\text { safety }\end{array}$ & $\begin{array}{l}\text { Fuel Production and Consumption } \\
\text { Maintenance Material Production } \\
\text { Noise-in-use }\end{array}$ & \\
\hline \multicolumn{3}{|l|}{ Transportation } & \\
\hline Disposal & & $\begin{array}{l}\text { Waste Management } \\
\text { Energy Process } \\
\text { Supplementary Materials } \\
\text { Residual value } \\
\text { Shredding } \\
\text { Dismantling }\end{array}$ & \\
\hline
\end{tabular}

Aspects and attributes are clusted in line with five phases of life cycle of a product. Besides Production, Using and Disposal phases, Transportations between manufacturing and using, and between using and disposal phase should be included. It is suggested that, as a comprehensive framwork for faciliating sustainable consumption, above aspects and attributes should be considered. In the table, aspect of Nature has been listed as a feature which should be assessed through entire life cycle. It is because long term consideration is required in these attributes. In currtent state of research, focus of Consumer Driven Framework was consentrated on aspects 
and attributes in Production phase and attibutes impact caused in manufacturing phase (as shown in grey area).

\section{Development of Consumer Driven Framework}

\subsection{Goal of Consumer Driven Framework}

This framework is designed to integrate all the possible attributes which used to evaluate social and environment performance, from which companies can choose to assess the sustainability for their products associated with manufacturing. Further developed instrument could function well in the mechanism of sustainable consumption as a facilitator. It well connects stakeholders and infrastructure and promotes entire system moving forward.

\subsection{Criteria of Developing Consumer Driven Framework}

The development of consumer driven framework is decided by following five criteria that suggested for developing a tool for promoting sustainable consumption (Shao et al. 2014a). First of all, the framework should be capable for meeting consumers' preferences regarding its focusing scope. From the perspective of consumers, the product is the interface they are facing and should make buying decision upon. So it will be much clear if the information is measured and provided based on unit of a product. Beyond considering the content and assessment unit, requirements from consumers are more critical on their presenting format of information. The goal of making information transparency could not be achieved without appropriate format. Therefore, the last three criteria are concerning information transparency ability of the approach. Unless the framework is designed and implemented from consumers' origination, it could hardly be properly applied for consumers. Besides, weather the information is recognizable and weather it has appropriate presenting format are key features. Furthermore, consumers need comparable information regarding their green preferences in order to make greener buying decision.

Therefore, the criteria of consumer driven framework consist of:

(a) Focus on consumers' preferences;

(b) Product based assessment;

(c) Consumers originated;

(d) Degree of recognition by consumers;

(e) Degree of comparability among same type of products.

Additionally, it considered applicability of attributes in the process of developing Consumer Driven Framework. 


\subsection{Structure of Consumer Driven Framework}

The selection of the dimensions of interest to be included in the final model has been based on the literature analysis that led into a preliminary list of associated attributes.

This preliminary consumer driven framework has two dimensions which indicate environmental impact and social impact. Aspects of Nature, Energy Using and Material Using are included in the dimension of environmental impact. Dimension of social impact has aspects of Human and Company Image. Detail attributes are listed in table 3 .

Table 3. The proposed list of key aspects and attributes of Consumer Driven Framework

\begin{tabular}{|c|c|c|c|}
\hline $\begin{array}{l}\text { Dimen- } \\
\text { sion }\end{array}$ & Aspect & \multicolumn{2}{|l|}{ Attribute } \\
\hline \multirow{20}{*}{$\begin{array}{l}\text { Envi- } \\
\text { ronmen- } \\
\text { tal } \\
\text { Impact }\end{array}$} & \multirow{3}{*}{$\begin{array}{l}\text { Material } \\
\text { Using }\end{array}$} & \multicolumn{2}{|c|}{ Reuse/recycling of resource (energy, material, product) } \\
\hline & & \multicolumn{2}{|c|}{ Raw Material Extraction } \\
\hline & & \multicolumn{2}{|c|}{ Specific Raw material consumption } \\
\hline & \multirow{3}{*}{$\begin{array}{l}\text { Energy } \\
\text { Using }\end{array}$} & \multicolumn{2}{|c|}{ Energy Efficiency } \\
\hline & & \multicolumn{2}{|l|}{ Renewable Energy } \\
\hline & & \multicolumn{2}{|c|}{ Specific energy consumption } \\
\hline & \multirow{14}{*}{ Nature } & Air & Life cycle global warming \\
\hline & & & Greenhouse gas emissions \\
\hline & & & Indoor Air pollution \\
\hline & & & Regional Ozone \\
\hline & & & Nitrogen Loading \\
\hline & & & Life cycle Air Quality \\
\hline & & Reducing water stress & Water quality/Drinking Water \\
\hline & & & Water Consumption \\
\hline & & Noise level & Average noise level in plant \\
\hline & & Biodiversity & Wilderness Protection (Eco region Protection) \\
\hline & & & Timber Harvest Rate \\
\hline & & & Agricultural Subsidies \\
\hline & & & Overfishing \\
\hline & & & Land \\
\hline \multirow{8}{*}{$\begin{array}{l}\text { Social } \\
\text { Impact }\end{array}$} & \multirow[t]{6}{*}{ Human } & Employee & Training \\
\hline & & & participation (human right) \\
\hline & & & Child labor \\
\hline & & & Working safety \\
\hline & & Customer & Satisfaction \\
\hline & & & Safety \& health \\
\hline & $\begin{array}{l}\text { Company } \\
\text { Image } \\
\end{array}$ & Law suit & \\
\hline & & Local community & \\
\hline
\end{tabular}

\section{Conclusion}

This research proposed a framework that aimed at evaluating social and environmental performances of a product in its production phase to help consumers to access the sustainability performance information of a product, and then enhance greener buying 
decision. The research piece presented in this paper is going to be developed further by introducing detailed formulas for indicators and validating through case studies. Therefore, the proposed framework contributes to the literature in the field development of facilitator in SPaC. The final proposal is a supporting tool for practitioners who can choose to assess sustainability for their products associated with manufacturing based on this framework. A fine-tuned version is thus expected to be released in the near future.

\section{Acknowledgement}

This research is conducted within the framework of the European Doctorate in Industrial Management (EDIM) which is funded by The Education, Audiovisual and Culture Executive Agency (EACEA) of European Commission under Erasmus Mundus Action 1 programmes.

\section{Reference}

Akenji L (2014) Consumer scapegoatism and limits to green consumerism. J Clean Prod 63:13-23. doi: 10.1016/j.jclepro.2013.05.022

Amacher GS, Koskela E, Ollikainen M (2004) Environmental quality competition and ecolabeling. J Environ Econ Manage 47:284-306. doi: 10.1016/S0095-0696(03)00078-0

Arena M, Ciceri ND, Terzi S, et al. (2009) A state-of-the-art of industrial sustainability: definitions, tools and metrics. Int. J. Prod. Lifecycle Manag. 4:

Bell S, Morse S (2008) Sustainability Indicators-Measuring the immeasurable?, 2nd ed. Earthscan, London $\bullet$ Sterling,VA

Brundtland H (1987) Our common future.

CSD (2001) Indicators of Sustainable Development: Guidelines and Methodologies.

Dahl AL (2012) Achievements and gaps in indicators for sustainability. Ecol Indic 17:14-19. doi: 10.1016/j.ecolind.2011.04.032

Freudenberg M (2003) Composite Indicators of Country Performance: A Critical Assessment. OECD Sci.

Ha H, Coghill K, Maharaj EA (2009) Current Measures to Protect E-Consumers ' Privacy in. doi: 10.4018/978-1-60566-012-7.ch006

Harrison R, Newholm T, Shaw D, Version E (2005) The Ethical Consumer. SAGE Publication 
Joung CB, Carrell J, Sarkar P, Feng SC (2012) Categorization of indicators for sustainable manufacturing. Ecol Indic 24:148-157. doi: 10.1016/j.ecolind.2012.05.030

Lehni M (1999) Ecoefficiencia World Business Council for Sustainable Development Presentation at WBCSD : Progress toward Sustainability.

OECD (2008) Promoting Sustainable Consumption-Good Practices in OECD Countries.

OECD (2009) Policy Brief: Sustainable Manufacturing and Eco-innovation: Towards a Green Economy.

Olsthoorn X, Tyteca D, Wehrmeyer W, Wagner M (2001) Environmental indicators for business: a review of the literature and standardisation methods. J Clean Prod 9:453-463. doi: 10.1016/S0959-6526(01)00005-1

Shao J, Taisch M, Ortega M (2014a) A Systematic Review on Information Transition Approaches of Sustainable Production and Consumption ( SPaC ). submitted

Shao J, Taisch M, Ortega Mier M (2014b) Sustainability Assessment Instruments for Consumers. 20th ICE Conf. - IEEE TMC Eur. Conf.

Singh RK, Murty HR, Gupta SK, Dikshit a. K (2007) Development of composite sustainability performance index for steel industry. Ecol Indic 7:565-588. doi: 10.1016/j.ecolind.2006.06.004

Singh RK, Murty HR, Gupta SK, Dikshit a. K (2009) An overview of sustainability assessment methodologies. Ecol Indic 9:189-212. doi: 10.1016/j.ecolind.2008.05.011

Taisch M, Shao J (2013) Critical Mapping of Sustainable Index Methodologies. IEEE Int. Conf. Ind. Eng. Eng. Manag.

Appendix A: List of indicators and references

\begin{tabular}{|c|c|c|c|}
\hline $\begin{array}{l}\text { Compass of } \\
\text { Sustainability }\end{array}$ & $\mathrm{CS}$ & $\begin{array}{l}\text { (Atkisson, } \\
2005 \text { ) }\end{array}$ & $\begin{array}{l}\text { Atkisson, B A , \& Hatcher, R L "The compass index of sustainability: A } \\
\text { five-year review", write for conference "Visualising and Presenting } \\
\text { Indicator Systems", Switzerland, } 2005\end{array}$ \\
\hline $\begin{array}{l}\text { Composite } \\
\text { Sustainability } \\
\text { Performance } \\
\text { Index }\end{array}$ & CSPI & $\begin{array}{l}\text { (Singh, } \\
\text { 2007) }\end{array}$ & $\begin{array}{l}\text { Singh, R K, Murty, H R, Gupta, S K, Dikshit, A K, "Development of } \\
\text { composite sustainability performance Index for steel industry", in Ecologi- } \\
\text { cal Indicators, 7, 565-588, } 2007\end{array}$ \\
\hline Eco-Indicator 99 & E99 & $\begin{array}{l}\text { (PRé, } \\
\text { 2001) }\end{array}$ & $\begin{array}{l}\text { Pré Consultants, "The Eco-indicator } 99 \text { - a damage oriented method for } \\
\text { life cycle impact assessment", in Methodology Report Available at: } \\
\text { http://www pre nl/, } 2001\end{array}$ \\
\hline $\begin{array}{l}\text { Environment } \\
\text { Performance } \\
\text { Index }\end{array}$ & EPI & $\begin{array}{l}\text { (WEF, } \\
\text { 2006) }\end{array}$ & http://epi yale edu/ \\
\hline $\begin{array}{l}\text { Ford of Europe's } \\
\text { Product Sustain- } \\
\text { ability Index }\end{array}$ & F-PSI & $\begin{array}{l}\text { (Fleming, } \\
2007)\end{array}$ & Fleming, J, Ford of Europe's Product Sustainability Index Cost, 2007 \\
\hline G Score & $\mathrm{G}$ & $\begin{array}{l}\text { (Jung, } \\
2001 \text { ) }\end{array}$ & $\begin{array}{l}\text { Jung, E, Kim, J, \& Rhee, S, "The measurement of corporate environmen- } \\
\text { tal performance and its application to the analysis of efficiency in oil } \\
\text { industry", in Journal of Cleaner Production, } 9(6), 551-563,2001\end{array}$ \\
\hline
\end{tabular}

